\title{
Processo de desenvolvimento para projetos tecnológicos: Uma abordagem baseada em survey
}

\author{
Roberto Cesar Durscki (USP) roberto.durscki@poli.usp.br \\ Marcelo Eduardo Soeke (PUCPR) marcelo.soeke@icet.pucpr.br \\ Robert Carlisle Bunet (PUCPR) robert@icet.pucpr.br \\ Sheila dos Santos Reinehr (PUCPR) ssr@icet.pucpr.br
}

\section{Resumo}

Este trabalho apresenta um processo de desenvolvimento de projetos computacionais acadêmicos desenvolvido com base em um survey feito com alunos da PUC-PR. Apresentarse-á a motivação para o desenvolvimento do processo, as dificuldades e carências dos alunos reveladas pelo survey, a influencia dos resultados da pesquisa no processo desenvolvido e, finalmente, o processo em si. As considerações finais do artigo discutem a relevância deste trabalho na formação dos novos profissionais da área tecnológica, reforçando as principais características do processo proposto.

Palavras chaves: Processo de desenvolvimento, projetos acadêmicos.

\section{Introdução}

Desenvolver projetos acadêmicos, antes de um investimento de esforço e tempo é um desafio e uma oportunidade de se descobrir de maneira prática, e sem grandes riscos, quais são os problemas e as dificuldades de planejar, controlar e desenvolver projetos.

Alunos de graduação, sobretudo em cursos que focam T.I., recebem oportunidades para participar de projetos cada vez mais complexos, especialmente, à medida que a tecnologia envolvida nesse ramo evolui muito rapidamente. Tal complexidade acaba gerando diversos fatores críticos durante o desenvolvimento de um projeto e se eles não forem gerenciados de maneira correta, acarretam problemas no desenvolvimento e conseqüentemente falhas de projeto.

Considerando que projetos acadêmicos na área tecnológica dispõem de escassos recursos, pouco tempo, integrantes inexperientes em gerência de projetos e pequenas equipes, torna-se difícil a aplicação de processos tradicionais ${ }^{1}$ em seu desenvolvimento. Isto motivou o desenvolvimento de um survey no meio universitário para determinar com precisão as principais dificuldades que os alunos vivenciam e as principais falhas que eles constatam em seus projetos. Com o resultado desta pesquisa desenvolveu-se um processo de produção voltado para as necessidades do meio acadêmico e que se propõe a ser uma ferramenta tanto no desenvolvimento desses projetos como na aprendizagem de engenharia de design e engenharia de software.

Mais especificamente, este processo permitirá aos seus usuários aumentarem seus conhecimentos sobre a forma de apresentação e utilização de processos de produção e, conseqüentemente, obter mais controle sobre a execução de seus projetos. Isto acontecerá através da execução de atividades estruturadas e seqüenciadas, fazendo o uso de modelos (templates) e diagramas de seqüência (workflows) definidos. O processo apresenta também, padrões de documentação que demarcam etapas do ciclo de vida do projeto e auxiliam as etapas seguintes.

Finalmente, o processo oferece uma maneira simplificada de gerenciar o trabalho da equipe, oferecendo definição de papeis, simbologias para cada papel, além da definição da

\footnotetext{
${ }^{1}$ Dentre estes processos podemos citar: PSP ${ }^{\circledR}, \mathrm{TSP}^{\circledR}$, processo unificado, entre outros.
} 
participação de cada papel nas diversas atividades que compõem o ciclo de vida do projeto.

\section{A pesquisa com os alunos de graduação}

O convívio dos autores, tanto na situação de professor como de aluno, com os cursos de graduação, salientaram as dificuldades dos estudantes em estruturar e em aplicar adequadamente os processos ensinados ao logo do curso em seus projetos. Isto motivou os autores a desenvolverem um processo de desenvolvimento voltado para esse meio e que pudesse, de fato, vir a ser usado pela academia.

Para assegurar a validade e a compatibilidade do processo com as reais necessidades dos alunos, os autores elaboraram um questionário para levantar os pontos específicos de dificuldade e assim balizar o desenvolvimento do processo.

Devido à condição de dois autores como professores da PUC-PR, decidiu-se por realizar um survey com os alunos desta instituição, mais especificamente com os alunos dos cursos de Engenharia e Ciência da Computação. No currículo da instituição, esses cursos demandam vários projetos de diversos portes de seus alunos, especialmente a partir do terceiro ano letivo.

Foram distribuídos 160 questionários entre os alunos dos dois últimos anos de ambos os cursos. A participação era voluntária, e para cada aluno eram entregues dois questionários para que estes pudessem descrever dois projetos julgados de maior relevância. Na prática, poucos alunos preencheram dois questionários, assim, obtiveram-se os seguintes números:

\begin{tabular}{|l|l|l|}
\hline & $\begin{array}{l}\text { Ciência da } \\
\text { Computação }\end{array}$ & $\begin{array}{l}\text { Engenharia da } \\
\text { Computação }\end{array}$ \\
\hline Alunos envolvidos & 30 & 50 \\
\hline Questionários entregues & 60 & 100 \\
\hline Questionários retornados & 35 & 62 \\
\hline Total Retornado & 97 \\
\hline
\end{tabular}

Tabela 1 - Distribuição dos questionários aos alunos da PUCPR.

O questionário foi desenvolvido em quatro partes para facilitar sua interpretação. As partes são as seguintes:

- Parte I: Tema, duração e natureza do projeto descrito;

- Parte II: Dificuldade e desempenho estimados e constatados ao longo do projeto;

- Parte III: Problemas constatados ao longo do desenvolvimento do projeto;

- Parte IV: Conhecimento e opinião sobre processos de desenvolvimento para projetos tecnológicos.

\section{Parte I}

A primeira parte do questionário serviu para posicionar os alunos e os projetos que seriam analisados, com destaque para as seguintes questões: em qual disciplina o projeto foi desenvolvido, qual o nível de especificidade da definição do tema (se o professor e/ou orientador definiu concretamente o assunto do projeto ou se houve um esforço do aluno em definir o seu tema), a duração do projeto e, finalmente, a natureza do projeto (software, hardware, software e hardware).

Constatou-se um grande número de projetos de tema livre (41\%), que mesmo não sendo a maioria, justificam que o processo preocupe-se com a estruturação das atividades de definição do projeto (análise de temas, fontes de conhecimento, levantamento de requisitos, etc).

No que toca a natureza dos projetos, constatou-se que a maioria integrava software e hardware 
(55\%), seguidos pelos projetos de software (41\%), que juntos correspondiam à esmagadora maioria. Assim decidiu-se que o processo cobriria tanto projetos exclusivos de software como projetos integrados.

\section{Parte II}

Esta etapa do questionário concentrou-se na percepção de dificuldade do aluno, ou seja, a diferença entre a dificuldade esperada e experimentada pelos alunos em seus projetos e, nos choques entre o valor atribuído ao trabalho pelo aluno e pelo professor avaliador.

Esta parte do questionário revelou que $31 \%$ dos entrevistados haviam estimado uma dificuldade inferior à constatada, o que justificou o desenvolvimento de atividades que cobrem análise de requisitos, levantamento e tratamento de riscos, escolha de temas, elaboração de cronograma, entre outras.

Outra informação foi que $22 \%$ dos alunos julgaram que seus projetos tiveram um desempenho melhor do que o valor expresso pela avaliação do professor / orientador (nota).

Esse comportamento revela problemas que devem ser cobertos pelo processo, como a falta de comunicação efetiva entre professor e/ou orientador e os alunos e, o levantamento deficiente de requisitos.

\section{Parte III}

A terceira parte do questionário era composta por uma lista de 19 sentenças que faziam referencia a problemas tradicionais de projeto. $\mathrm{O}$ aluno deveria assinalar os itens que identificasse ter vivenciado em seu projeto.

Para fins de simplificação os autores separaram o processo em quatro estágios de evolução e desenvolveram questões para cada estágio. Essa separação não era evidente para o aluno já que as questões não estavam de forma seqüencial, no entanto, simplificaram a interpretação das respostas, pois evidenciavam onde residiam as maiores dificuldades.

Apesar do grande número de ocorrências em todas as fases, ficou claro que a maior dificuldade concentra-se no inicio do projeto (primeiro e segundo estágios) onde $41 \%$ dos alunos assinalaram dificuldades. Mais detalhadamente as dificuldades estavam nas etapas de definição de tema e escopo, levantamento de requisitos e design preliminar.

\section{Parte IV}

A quarta e última parte do questionário teve como objetivo avaliar o conhecimento e a aceitabilidade dos processos tradicionais de desenvolvimento, bem como a validade e a perspectiva de utilização de um processo voltado ao meio acadêmico.

Constatou-se que a maioria dos alunos (61\%) conhece processos tradicionais de desenvolvimento, mas no entanto somente (39\%) utilizam algum deles. Além disso, $96 \%$ dos alunos consideraram válido o desenvolvimento de um processo voltado para o meio acadêmico e, ao serem questionados sobre submeterem-se ao processo, mesmo que isso exigisse maior disciplina, $67 \%$, responderam que sim.

Concluída a pesquisa foi possível iniciar o desenvolvimento do processo proposto com mais confiança e objetividade. Os autores já dispunham de diversas idéias para o projeto, no entanto, os resultados mostraram concentrações de dificuldades no inicio do processo de desenvolvimento, assim como, problemas claros de definição de tema e comunicação com os professores / orientadores. Tudo isso influenciou o desenvolvimento do processo que será exposto detalhadamente a seguir. 


\section{O Processo Proposto}

Os projetos acadêmicos, de cunho tecnológico, seguem seu desenvolvimento através de um ciclo de trabalho evolutivo, facilmente identificável e peculiar. Tal ciclo de trabalho, também chamado de ciclo de vida, é marcado pela evolução do projeto em termos quantitativos e qualitativos e, desconsiderando variações de projetos de natureza específica, possuem uma forma típica de serem representados.

Baseado nos resultados do survey realizado, e na própria experiência dos autores, identificaram-se quatro estágios principais no desenvolvimento dos projetos acadêmicos. Cada estágio representa uma evolução qualitativa e quantitativa do projeto, em termos de pesquisa, análise, experimentação e atividades de avaliação. Esta evolução reflete a aproximação do projeto de seus objetivos finais.

O ciclo de vida do processo proposto é baseado no tradicional modelo cascata, com a adição de características incrementais evolutivas. Esta idéia partiu da constatação da facilidade de compreensão e aplicação do modelo cascata pelos alunos de graduação, que geralmente adotam tal fluxo de trabalho sem mesmo conhecer formalmente o modelo.

Segundo Kruchten (2000), a abordagem cascata tende a mascarar os riscos reais do projeto até que seja tarde demais para fazer qualquer coisa significativa quando a isso.

Na década de 80, Barry Boehm propõe uma abordagem de desenvolvimento de software orientada a identificar e tratar riscos de forma iterativa e incremental, o ciclo espiral de Boehm (1988). Esta abordagem reconhece as dificuldades impostas pelo modelo cascata e prevê que, a cada loop da espiral se complete uma fase, reduzindo os riscos de insucesso.

De maneira a conscientizar os alunos sobre a importância de trazer para as fases iniciais do desenvolvimento, problemas que comumente surgem apenas na conclusão dos projetos pelo modelo cascata, o processo recomenda algumas práticas do modelo incremental evolutivo, como a validação parcial através de protótipos e modelos de simulação, a contínua interação entre todos os envolvidos no projeto, e o monitoramento contínuo das mudanças e os riscos associados ao projeto.

Outra característica chave é a utilização da abordagem da Análise Essencial, proposta por Edward Yourdon (1992), e orientada a eventos, ao invés da UML (Unified Modeling Language) para especificar o projeto. Esta escolha se justifica na medida que foi diagnosticado, através do survey realizado, que a Análise Essencial é mais facilmente compreendida pelos alunos de graduação e, apesar de não ser voltada para representar arquiteturas orientadas a objetos, não compromete a qualidade da modelagem.

\section{O Ciclo de Vida}

Como definido anteriormente, o processo de produção proposto divide o ciclo de vida dos projetos em quatro estágios de características bem definidas. As fronteiras entre os estágios são delimitadas pela evolução de conjuntos específicos de subprodutos, ou Marcos de Transição, do desenvolvimento. Os estágios estabelecidos e os principais subprodutos são:

- Estudo do Problema: A primeira preocupação que os alunos devem ter quando iniciam um projeto é a certeza sobre o entendimento do problema que se pretende atacar. Uma vez conhecido o problema, deve-se trabalhar com o objetivo de definir adequadamente o escopo da solução proposta. Estas constatações ficam claras quando analisados os resultados das partes II e III do questionário. Com o intuído de reforçar estes pontos, o primeiro estágio do processo oferece fluxos de trabalho que definem as atividades essenciais para avaliar a viabilidade do projeto proposto, estabelecer um escopo adequado, e obter o modelo ambiental do projeto. 
- Aprimoramento da Solução: Estabelecido o escopo do projeto e definida a representação do ambiente, o próximo objetivo é propor uma arquitetura candidata, que deve ser validada ainda nesta fase inicial do projeto. Ainda com o intuito de atuar sobre os pontos falhos, mais comuns, constatados pelo survey, o processo orienta os desenvolvedores com relação às principais questões que devem ser levantadas durante a definição de uma arquitetura candidata. Dentre estas questões pode-se citar a escolha da melhor ferramenta de avaliação (protótipos, simulações, modelos matemáticos, etc), e a análise critica do modelo comportamental do sistema, formalizado durante este estágio.

- Construção da Solução: Este estágio do processo é mais longo do desenvolvimento e o que produz o resultado mais tangível do projeto: o produto em si. Durante o estágio os recursos são envolvidos intensamente, e a coordenação do esforço deve ser cautelosamente administrada. Cada componente da arquitetura é produzido, testado e integrado ao produto final. O processo limita-se a orientar a execução destas atividades, sem definir propriamente as ferramentas que devem ser empregadas, garantindo assim a flexibilidade em relação à tecnologia, e às técnicas de implementação preferidas pela equipe de desenvolvimento.

- Entrega do Projeto: Este estágio visa conscientizar os estudantes que o produto acabado não significa que o projeto está concluído. O processo orienta sobre a validação do produto em seu ambiente alvo, sobre a compilação dos resultados do projeto, e sobre a preparação e apresentação final destes. O processo encerra com o fechamento do projeto (incluindo orientações sobre uma possível defesa de projeto) e com instruções sobre a documentação das lições aprendidas.

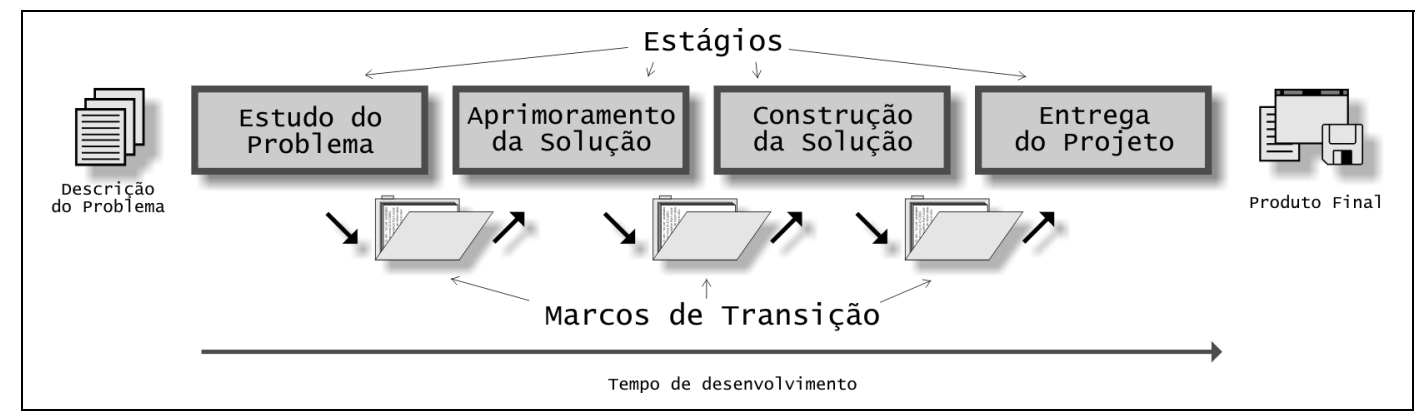

Figura 1 - Visão geral do ciclo de vida do processo.

\section{A Composição dos Estágios}

Cada estágio do ciclo de vida do processo foi estruturado sob uma base de elementos simples e de fácil compreensão, que trazem resultados diretos ao projeto, de maneira a tornar o processo uma ferramenta para os estudantes e não uma barreira contra seus objetivos.

Os estágios são constituídos por uma seqüência linear de macro-atividades. São precedidos por um conjunto de artefatos de entrada e concluídos quando seus Marcos de Transição são dados como concluídos para a fase em que se encontram. As macro-atividades, por sua vez, são compostas de micro-atividades que estão dispostas de maneira mais complexa, já que envolvem paralelismo e desvios condicionais (pontos de decisão). Os principais elementos dos estágios são:

- Macro-atividade: é um fluxo de trabalho envolvendo um conjunto de micro-atividades e decisões de projeto. Uma macro-atividade é uma representação gráfica do fluxo, e indica ao usuário quais micro-atividades devem ser executadas, se podem correr em paralelo ou apenas em ordem seqüencial, e quais caminhos devem ser tomados de acordo com decisões de projeto que o processo indica em determinadas etapas do desenvolvimento. 
- Micro-atividade: é uma atividade particular apresentada de maneira detalhada ao usuário do processo. Cada micro-atividade é composta por uma breve definição de seu propósito, um método, ou melhor, forma de desempenhar a atividade, sugerido, uma seção que define quais papéis devem participar da atividade, e o que cada um irá executar. Por fim, uma seção de artefatos que indicam quais são as entradas e produtos desta atividade e como os artefatos devem ser criados ou modificados ao longo da atividade.

- Papéis: é um conjunto de responsabilidades similares que são designadas para uma pessoa específica em um momento específico do desenvolvimento. A definição e associação de papeis aumenta a produtividade sendo que um papel não é necessariamente equivalente a uma pessoa, ele pode e deve ser re-atribuído durante o processo de desenvolvimento.

- Artefatos: correspondem a todos os subprodutos úteis do projeto, obtidos ao longo do desenvolvimento deste. Os artefatos agregam um valor importante uma vez que eles documentam e representam a evolução concreta do projeto. O processo propõe um conjunto de artefatos úteis para a gerencia das principais informações do projeto, bem como fornece modelos auto-explicativos dos artefatos mais relevantes para o projeto.

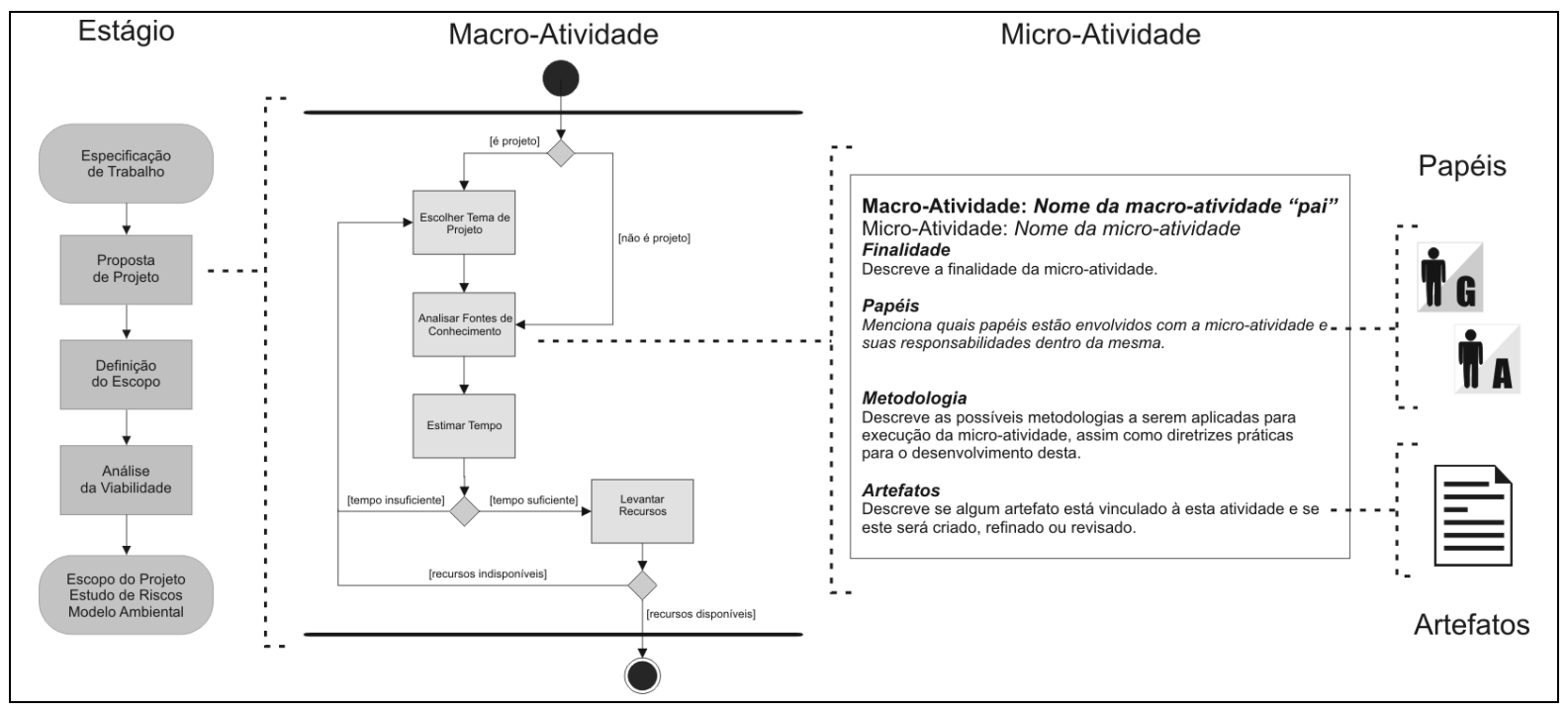

Figura 2 - Interrelação das principais estruturas do processo.

\section{Atividades Complementares}

Além das atividades específicas de cada fluxo de trabalho, o processo apresenta um grupo especial de atividades, chamadas de complementares, que são muito importantes e que devem ser cuidadosamente executadas ao longo de todo o ciclo de vida do desenvolvimento. Os objetivos destas atividades são facilitar o gerenciamento das tarefas de desenvolvimento, organizar a atribuição de trabalho, manter a coesão entre os membros da equipe e melhorar a qualidade do projeto e seus resultados. Estas atividades são:

- Gerência de Configuração: esta conhecida disciplina da engenharia de software foi adaptada para a realidade academica e explicada de forma bastante simplificada. No entanto, o processo sugere muitas maneiras de executar a gerência de configuração das formas mais simples a algumas alternativas mais elaboradas. Aponta também os problemas, comumente encontrados, em projetos acadêmicos que não adotam nenhum mecanismo de gerencia de configuração, motivando a adoção desta prática através dos benefícios que esta proporciona.

- Acompanhamento de Mudanças: acompanhar as mudanças e a evolução dos requisitos é uma atividade muito importante para qualquer projeto. Nesta boa prática os estudantes são 
alertados sobre os tradicionais problemas de requisitos mutantes e das medidas de segurança que devem ser tomadas para prevenir que o projeto siga em desacordo com seus requisitos. Além de se preocupar com o impacto das mudanças nos requisitos do projeto, os usuários do processo são orientados com relação ao gerenciamento dos riscos associados com a natureza dinâmica dos requisitos. Esta atividade complementar oferece orientações em como determinar, classificar e gerenciar os riscos.

- Atribuição de Papéis: por fim, esta atividade mostra aos usuários quais papéis fazem parte do processo proposto, quais são as responsabilidades de cada papel, e como e quando estes papeis devem ser atribuidos para os membros da equipe de desenvolvimento. Intuitivamente, os alunos de graduação trabalham com um conceito não formalizado de papéis, e quando encontram-se em equipes de desenvolvimento, conseguem distribuir estes papéis conforme o perfil de cada membro. Esta atividade apresenta formalmente os papéis importantes para uma equipe pequena, e encoraja os membros a alternarem os papéis ao longo do projeto para melhor compreender as responsabilidades associadas.

Essas atividades complementam o processo, pois, o fato de um alunos estar seguindo o fluxo de trabalho do processo, não implica que ele o esteja executando de forma organizada. A execução de atividades simples como gerencia de configuração e de riscos ao longo de todo o prjeto aumentam muito a qualidade do desenvolvimento e, incorporam um maior grau de maturidade nos estudantes, que aprenderão as vantagens destas práticas em seus projetos.

\section{Considerações Finais}

Um processo de desenvolvimento para projetos acadêmicos pode ser uma ferramenta poderosa na preparação de novos profissionais da área tecnológica. O contato dos estudantes com um processo simples, focado no trabalho em equipe e inserido no contexto dos cursos de graduação, permite a estes descobrirem por si só a maioria das questões relacionadas ao desenvolvimento de projetos.

A ênfase dada na definição e distribuição de papéis, bem como a correlação destes com os estágios de desenvolvimento oferece aos estudantes uma excelente oportunidade de identificar a contribuição dos diferentes papéis envolvidos nos vários estágios do ciclo de vida dos projetos.

A opção por utilizar artefatos ao longo do processo de desenvolvimento, é uma questão bastante importante deste trabalho. Esta abordagem pretende mostrar uma nova visão aos estudantes sobre a importância da documentação. Geralmente estes documentos são vistos como "inimigos", que significa que os estudantes tendem a vê-los como desperdício de tempo precioso que poderia ser utilizado no desenvolvimento em si. O objetivo final é mostrar aos estudantes que os artefatos (como subprodutos do projeto) são ferramentas muito importantes para o desenvolvimento como um todo, e que se eles forem construídos gradativamente e seguirem a evolução do projeto eles podem se revelar partes simples e intrínsecas do desenvolvimento.

Como contribuição à engenharia, o processo proposto irá preparar os estudantes para encarar novos processos e ferramentas de desenvolvimento, uma vez que eles formarão sólidas bases nos principais conceitos básicos e disciplinas. Esta preparação irá prevenir o choque tradicional que estudantes de graduação têm quando encontram pela primeira vez processos bem estabelecidos no mercado.

Finalmente, o projeto abordado por este artigo é um subproduto do projeto MILPS ${ }^{2}$ de pesquisa científica do grupo Qualidade de Processo, Projeto e Produto de Software da PUC-

\footnotetext{
${ }^{2}$ Modelo de Integração de Linha de Produção de Software com TSP e PSP - Processo Institucional n. ${ }^{\circ}$ 55.2217/02-6.
} 
$\mathrm{PR}$, financiado parcialmente com recursos do $\mathrm{CNPq}^{3}$, entidade governamental brasileira promotora do desenvolvimento científico e tecnológico.

\section{Referencias Bibliográficas}

BOEHM, BARRY. (1988) - A Spiral Model for Software Development and Enhancement. Computer, vol. 21, número 5, Maio 1988, pp. 61-72.

KRUCHTEN, PHILIPPE. (2000) - The Rational Unified Process - An Introduction - Second Edition. Reading, MA: Addison-Wesley Publishing Company, 2000, 298 p.

YOURDON, EDWARD. (1992) - Análise Estruturada Moderna. RJ: Editora Campus, 1992, 835 p.

\footnotetext{
${ }^{3}$ Conselho Nacional de Desenvolvimento Cientifico e Tecnológico.
} 